\title{
Research on 380V Neutral Wire Over-current Alarm Device
}

Liu Bo ${ }^{1}$, Wang Qinghao ${ }^{1}$, Liu Lin ${ }^{1}$, Zhang Jiayan ${ }^{1}$, Liu Xiao ${ }^{1}$, Li Na ${ }^{1}$, Shi Feng ${ }^{1}$, $\mathrm{Li} \mathrm{Tianci}^{1}$, Zhang Fuliang ${ }^{1}$, ZhangBo $^{1}$, Li Feng ${ }^{2}$, Liu Chenyang ${ }^{1}$, Liu Min ${ }^{1}$

${ }^{1}$ Fushun Power Supply Company, Liaoning Electric Power Company Limited, State Grid, China,

${ }^{2}$ Information and Communication Branch, Liaoning Electric Power Company Limited, State Grid, China,

fushunpowersupply@163.com

Keywords: TN-C; TN-S; neutral line outage; over current alarm; harmonic current

Abstract. Through the analysis of TN-C and TN-S connection mode, this paper expounds the advantages and disadvantages of TN, the voltage distribution of the load is introduced through an example, and further introduces the necessity of developing neutral wire over current alarm device in the distribution network, and it discusses the composition, working principle and using method of the neutral wire over current alarm device. Through the application in the field, it is proved that the use this device for distribution network can prevent the neutral line outage and have the advantages of early warning. The development can improve corporate image, and has a wide range of promotion value and application prospects.

\section{Introduction}

$\mathrm{TN}-\mathrm{C}$ or TN-S connection is widely used in the current distribution of $380 \mathrm{~V}$. TN-C is usually said to be the 3 phase 4 wire; TN-S is usually the 5 phase 3 wire[1,2]. The two wiring are shown in Figure 1 and Figure 2.

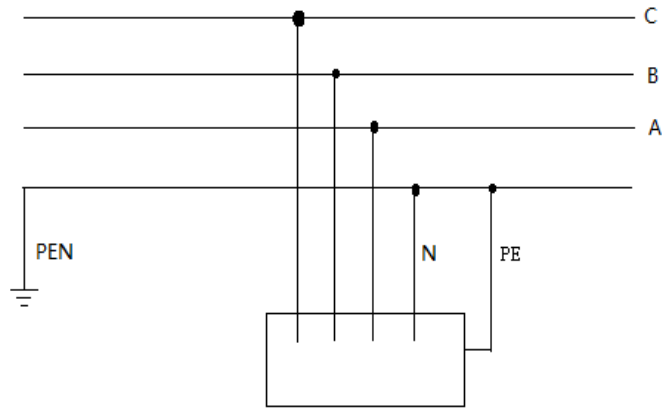

Fig. 1 TN-C wiring schematic drawing

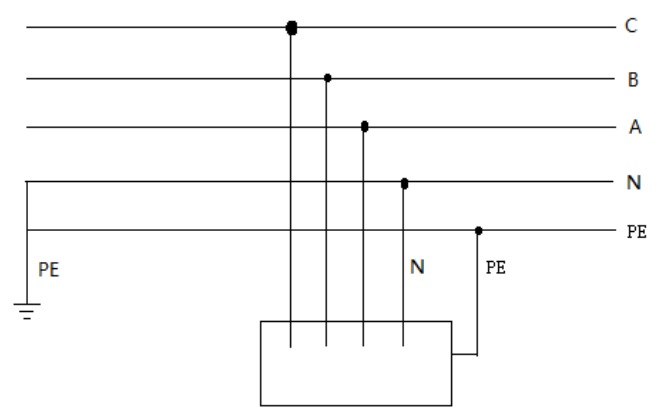

Fig. 2 TN-S wiring schematic drawing

The comparison of the two wiring is shown in Table 1[3-5].

Table 1 The advantages and disadvantages of TN-C or TN-S

\begin{tabular}{|c|c|c|}
\hline \multirow[b]{2}{*}{ TN-C } & advantages & $\begin{array}{l}\text { 1. small investment cost, simple wiring, and save one line } \\
2 \text {, Do not need the independent grounding grid for no running } \\
\text { equipment }\end{array}$ \\
\hline & disadvantages & $\begin{array}{l}\text { 1.three-phase unbalanced, single-phase load, harmonic current, the } \\
\text { PEN line in the current, shell charged } \\
2 \text {, when the equipment and PEN line contact is extremely easy to } \\
\text { produce sparks } \\
3 \text {. When the PEN line is in contact with bad and broken line, the } \\
\text { voltage of the equipment casing is } 220 \mathrm{~V} \text {. }\end{array}$ \\
\hline \multirow[t]{2}{*}{ TN-S } & advantages & $\begin{array}{l}1 \text {, PE line is a separate ground, usually does not pass through the } \\
\text { working current, it is only in the event of the fault current, there is no } \\
\text { interference with the electronic device because the normal Pe is zero } \\
\text { potential, } \\
2 \text {, no spark phenomenon over the ground } \\
3 \text {, suitable for the supply of data processing and precision electronic } \\
\text { instruments }\end{array}$ \\
\hline & disadvantages & $\begin{array}{l}\text { 1. one more wire in the loop } \\
\text { 2. suitable for the place without a separate grounding grid }\end{array}$ \\
\hline
\end{tabular}




\section{Damage of the neutral line outage}

(1)Function of neutral line

When the TN system of the low voltage power distribution network is running, it will cause the neutral point drift and generate the displacement voltage due to the unbalanced three-phase load and the single phase to ground fault. At this time, the neutral line will flow a lot of electric current, sometimes can reach hundreds of amps. Neutral line has the displacement voltage; three-phase voltage is unbalanced, causing a phase voltage higher than the maximum allowable voltage and a phase voltage lower than the minimum allowable voltage, so that the device can not run normally. In addition, when the center line is broken, the user's electrical equipment will damage.

(2)Hazard of neutral line outage

Assume lamp 1=100W, lamp 2=200W, lamp 3= lamp 4=60W, as shown in Figure 3.

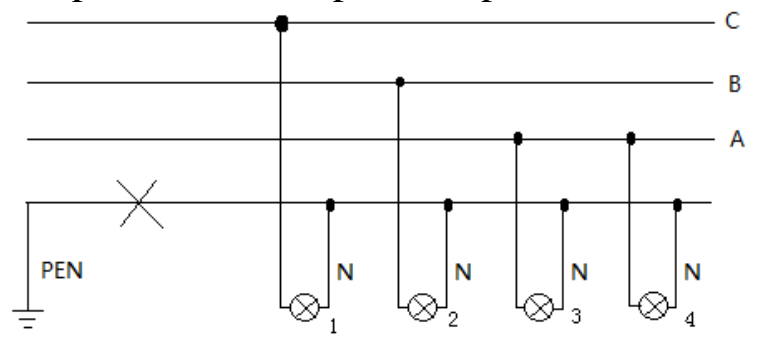

Fig. 3 example graph when the neutral line is broken

The equivalent circuit diagram of the middle line outage is shown in Figure 4, The lamp resistance values are,

$\mathrm{R} 1=\mathrm{U} 2 / \mathrm{P}=220 * 220 / 100=484 \Omega ; \mathrm{R} 2=\mathrm{U} 2 / \mathrm{P}=220 * 220 / 200=242 \Omega$;

$\mathrm{R} 3=\mathrm{R} 4=\mathrm{U} 2 / \mathrm{P}=220 * 220 / 60=806 \Omega$.

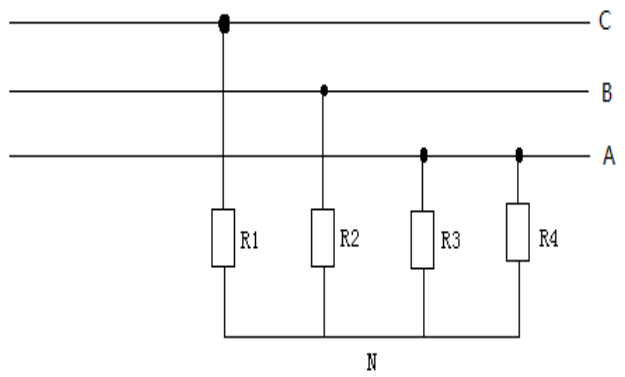

Fig. 4 equivalent circuit diagram of the neutral line outage

For circuits composed of A and B, the equivalent circuit is shown in Figure 5.

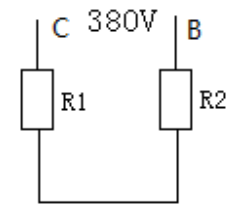

Fig. 5 The equivalent circuit of $\mathrm{B}$ and $\mathrm{A}$

Then $\mathrm{I}=380 /(\mathrm{R} 1+\mathrm{R} 2)=380 /(484+242)=0.52 \mathrm{~A}$

The voltage $\mathrm{U} 1$ on the lamp 1 is $\mathrm{U} 1=\mathrm{I} * \mathrm{R} 1=0.52 * 484=252 \mathrm{~V}$

The voltage U2 on the lamp 2 is $\mathrm{U} 2=\mathrm{I} * \mathrm{R} 1=0.52 * 242=128 \mathrm{~V}$

So, the distribution voltage $252 \mathrm{~V}$ on lamp 1 is higher than the rated voltage $220 \mathrm{~V}$, lamp1 is burnt out; and, the distribution voltage $128 \mathrm{~V}$ on lamp 2 is lower than the rated voltage $220 \mathrm{~V}$, lamp 2 can not work properly. So it must ensure that the neutral line will be not outage.

\section{Composition of over current alarm device}

At present, there is no current monitoring system in the distribution network. In order to ensure the normal operation of the equipment, to avoid equipment failure caused by the abnormal operation of the neutral line, it is necessary to develop a power distribution network neutral current to monitor and alarm the neutral current, and the composition of over current alarm device is shown 
in Figure 6.

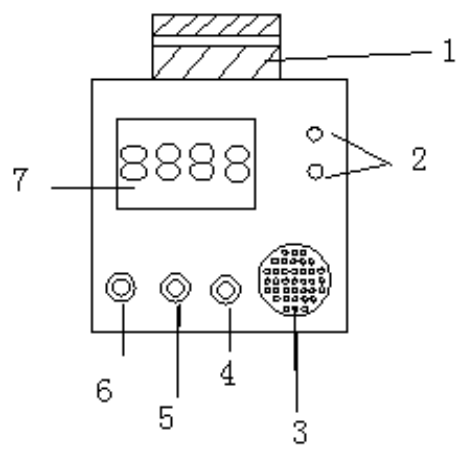

Fig.6 The composition panel of neutral current alarm device

1.sampling and fixed part; 2.current setting button ;3.alertor; 4.alarm lamp; 5.red light; 6. yellow light;

7.current display

\section{Use steps of the alarm device}

The neutral current alarm device is installed in the central line near the power supply side $1-2 \mathrm{~m}$. The rated current can be calculated according to the transformer capacity, we take $20 \%$ rated current as the first current value of the current setting unit, take $25 \%$ Ie as the second current value of the current setting, take $30 \% \mathrm{Ie}$ as the third current value of the current setting unit. The current size of the line can be clearly seen through the current display unit, when the current exceeds $20 \%$ Ie, the sound and light alarm unit lights yellow; when the current exceeds 25\%Ie, the sound and light alarm unit lights red, while the alarm sound; when the current exceeds 30\%Ie, sound and light alarm lights, while a strong alarm sound. When the abnormal operation of the middle line, the maintenance personnel can find fault in time, according to the fault type of the correct treatment, to ensure the normal operation of equipment.

\section{Application on spot}

The neutral current alarm device has been developed, and applied in the July 8, 2015 Fushun DongFangShangCeng housing estate, No.3 transformer neutral line of No. 1 .ring main unit. Specific as follows: the people's activity center in NO. 25-3 building held community activities at 6:00pm on that night, People living near the active center have arrived, the power of the center supply by No.3 transformer A phase. At that time, the residents living in No.3 transformer's BC phase participate in community activities at the A phase of the 25-3 building, it made A phase load suddenly increased, BC two phase load suddenly reduced, causing the neutral line current Ie exceeded the design value of $20 \%$, the actual value was $22.5 \%$ Ie, sound and light alarm unit lights yellow. However, with the activities of the more the more, the development of a variety of activities carried out gradually, with increasing the amount of electricity, neutral wire current rose from 22.5\%Ie to $27.6 \%$ Ie .distribution network neutral line over current alarm device and sound alarm, while the alarm sound, the final neutral line current reached 31.6\%Ie. sound and light alarm unit lights, also issued a strong warning sound, the distribution repairman rushed to the scene after 10 minutes, disposed the neutral line displacement voltage, then eliminated these hidden danger and avoided a power distribution equipment accident caused by excessive neutral current.

\section{Conclusion}

Distribution network neutral current alarm device can be completed on the neutral line current monitoring and alarm work, to ensure the normal operation of the equipment, also to avoid accidents caused by abnormal operation of the neutral line. The device has high sensitivity, accurate and reliable. It can reduce the dispute between user and power supply enterprises and improve the image of the enterprise. The device has a wide range of promotion value and application prospects. 


\section{References}

[1] Ping Shaoxun, Zhou Yufang. Analysis of Power System Neutral Point Grounding and Running. China Power Press, 2010

[2] Tan Qiong, Li Jinglu, Li Zhiqiang, Lightning Protection Technology of Mountainous Grid. China Water Power Press, 2011

[3] Yin Kening, Principle of Transformer Design. China Power Press, 2010

[4] Chen Jiabin, Gao Xiaofei. The Lightning Protection and Grounding Practical Techniques of Electrical. China Water Power Press, 2010

[5] Fang Daqian. The Quick Search Handbook for Transformer. China Water Power Press, 2004 